\title{
Incidence and risk factors associated with postoperative stroke in the elderly patients undergoing hip fracture surgery
}

Lili Yu ${ }^{1,2+}$, Yanbin Zhu ${ }^{3,4 \dagger}$, Wei Chen ${ }^{3,4}$, Hui Bu ${ }^{1,2^{*}}$ and Yingze Zhang ${ }^{3,4,5^{*}}$ (D)

\begin{abstract}
Objectives: Stroke is one of the rare but devastating complications after hip fracture in the elderly. By far, there is still scarce data on postoperative stroke in elderly patients with hip fractures.

Methods: This was a retrospective study of prospectively collected data. Between October 2014 to December 2018, patients aged above 65 years who underwent operative treatment for hip fractures were included. Inpatient medical surveillance and scheduled telephone follow-up at 1, 3, 6, and 12 months after operation was conducted to identify who developed an incident stroke. Variables of interests were extracted from patients' inpatient medical records. Univariate analysis and multivariate logistic regression analysis were used to identify the independent risk factors associated with stroke.
\end{abstract}

Results: During the study period, a total of 3743 patients were included, among whom 56 were found to have a stroke after operation, representing an incidence of $1.5 \%(95 \% \mathrm{Cl}, 1.1$ to 1.9\%). The multivariate analyses showed that advanced age (1-year increment; $\mathrm{OR}, 1.32 ; 95 \% \mathrm{Cl}, 1.08$ to 1.48), history of previous stroke $(\mathrm{OR}, 4.79 ; 95 \% \mathrm{Cl}$, 1.86 to 6.56$)$, ASA III and above (OR, 2.62; $95 \% \mathrm{Cl}, 1.27$ to 3.68), long-term use of aspirin (OR, 3.63; $95 \% \mathrm{Cl}, 1.41$ to 4.78), and elevated RDW level (each increment of $1 \%, \mathrm{OR}, 1.21 ; 95 \% \mathrm{Cl}, 1.02$ to 1.36 ) were independently associated with postoperative stroke.

Conclusions: Although most are not modifiable, these risk factors help in counseling patients regarding the risk of postoperative stroke, individual risk stratification, and targeted optimization of medical conditions and should be firmly kept in treating surgeon's mind.

Keywords: Epidemiology, Hip fracture, Multivariate analyses, Risk factors, Stroke

\footnotetext{
*Correspondence: buhuinuro64@126.com; drzhang2013@126.com

${ }^{\dagger}$ Lili Yu and Yanbin Zhu contributed equally to this work.

'Department of Neurology, The 2nd Hospital of Hebei Medical University, Shijiazhuang 050000, Hebei, People's Republic of China

${ }^{3}$ Department of Orthopaedic Surgery, The 3rd Hospital of Hebei Medical University, Shijiazhuang 050051, Hebei, People's Republic of China Full list of author information is available at the end of the article
}

C C The Author(s). 2020 Open Access This article is licensed under a Creative Commons Attribution 4.0 International License, which permits use, sharing, adaptation, distribution and reproduction in any medium or format, as long as you give appropriate credit to the original author(s) and the source, provide a link to the Creative Commons licence, and indicate if changes were made. The images or other third party material in this article are included in the article's Creative Commons licence, unless indicated otherwise in a credit line to the material. If material is not included in the article's Creative Commons licence and your intended use is not permitted by statutory regulation or exceeds the permitted use, you will need to obtain permission directly from the copyright holder. To view a copy of this licence, visit http://creativecommons.org/licenses/by/4.0/. The Creative Commons Public Domain Dedication waiver (http://creativecommons.org/publicdomain/zero/1.0/) applies to the data made available in this article, unless otherwise stated in a credit line to the data. 


\section{Introduction}

With the aggravation of aging in the worldwide, osteoporotic fracture has become one of the major threats to health-care systems $[1,2]$. As a typical osteoporotic fracture, hip fracture is anticipated to increase to 4.5 to 6.3 million by 2050 [3], with Asian being the mostly affected population. A large epidemiological survey in China suggested hip fracture is the second largest type of fracture in the elderly population, only following the distal radius fracture [4]. Notable as the "last fracture" in one's lifetime, hip fracture seriously affects the limb function and quality of life and substantially increases the social and family burden [5]. The complications after hip fractures have always been a focus subject, particularly the cardiacerebrovascular disease including postoperative stroke [6]. Indeed, there is a large proportion of overlapping factors between hip fracture and stroke, such as advanced age, comorbidity, impaired vision, weakened muscle strength, cognitive impairment, and susceptibility to falls, so the incidence of stroke after hip fracture is increased by several folds [7-9]. In addition, during acute therapy in patients with hip fracture, traumatic stress, perioperative use of medications, surgical intervention, iatrogenic trauma, and postoperative pathophysiological changes also increased the risk of stroke $[6,10]$.

Previous studies have made various attempts to investigate the incidence and risk factors for postoperative delirium after hip fracture surgeries [11-14], or incident hip fracture after the stroke $[8,9,15]$. However, there is still a lack of epidemiologic data on postoperative stroke following surgery of hip fractures. By far as we know, there has been no study specifically addressing the incidence and risk factors associated with postoperative stroke following hip fracture surgeries. By comparison, most of the studies focused on surgical methods (hip arthroplasties or fracture repair) [16, 17], other bone fracture locations [18], or the crude impact of hip fracture on stroke $[6,19]$. As such, the extrapolation of these results to studies of hip fractures might be inappropriate.

In this study, we used the prospectively collected data in university-affiliated orthopedics hospital, with aims to investigate the incidence rate of postoperative stroke after hip fracture surgeries and identify some independent risk factors associated with occurrence of stroke.

\section{Materials and methods}

All methods used in this study were performed in accordance with the STROCSS (Strengthening the Reporting of Cohort Studies in Surgery) guidelines.

Data used in this study were extracted from the database of Surgical Site Infection in Orthopaedic Surgery (SSIOS). The SSIOS database is a prospectively maintained and updated database of all the data on hospitalized patients undergoing orthopedic surgeries, beginning from 1 October 2014 and updated yearly. The initial aim of SSIOS was to evaluate the surgical site infection (SSI) after orthopedic surgery using the method of medical surveillance during hospitalization stay and scheduled telephone visits after discharge. Before the SSIOS commenced, it was approved by the ethics committee of the 3rd Hospital of Hebei Medical University (No. 2014-015-1). All the participants have provided their written informed consent.

In this study, patients with hip fractures surgically treated in our hospital from October 2014 to December 2018 were included. Inclusion criteria were patients aged 65 years or older, definite diagnosis of hip fracture (femoral neck fracture or intertrochanteric fracture) caused by low-energy trauma (fall from standing height), surgical treatment (hip replacement or osteosynthesis), complete data available in medical records, and followup period for at least 12 months. Exclusion criteria were fractures caused by high-energy trauma, combined fractures in other locations, conservative treatment, patients with incomplete medical records, loss to follow-up, or death during follow-up period.

\section{Definition and diagnosis of stroke}

Stroke was defined as acute onset of a neurologic deficit that corresponded to an arterial vascular territory of the cerebral hemispheres, brainstem, or cerebellum. Stroke was classified as hemorrhagic and ischemic stroke (cerebral infarction and transient ischemic attack (TIA)). Stroke was diagnosed based on patients' consciousness, limb performance, head CT, and MRI performance.

\section{Data extraction}

Patient data were extracted from electronic medical records. Baseline characteristics included residence (urban or rural), age, gender, body mass index (BMI), cigarette smoking, alcohol consumption, and co-morbidities (hypertension, diabetes, rheumatoid arthritis, history of ischemic heart disease, previous any fracture, previous history of stroke, and long-term use of aspirin ( $>6$ months before the hip fracture occurrence)). Fracture and surgery-related data included preoperative interval (between fracture occurrence and operation), the type of fracture (femoral neck or intertrochanteric), injury mechanism (high or low-energy injury), operative duration, blood loss, anesthesia type, and American Society of Anesthesiologists (ASA) classification, as well as laboratory indexes such as total protein (TP), albumin (ALB), alanine transaminase (ALT), aspartate transaminase (AST), preoperative red blood cell (RBC), white blood cell (WBC), hemoglobin (HGB), hematocrit (HCT), platelet (PLT), red blood cell distribution width (RDW), serum total cholesterol (TC), triglyceride (TG), 
low-density lipoprotein (LDL-C), high-density lipoprotein (HDL-C), and very low-density lipoprotein (VLDL). The BMI $\left(\mathrm{kg} / \mathrm{m}^{2}\right)$ was subgrouped using the criteria recommended by the Chinese working group on obesity: normal (18.5-23.9), underweight $(<18.5)$, overweight (24.0-27.9), and obesity ( $\geq 28.0$ ). Low-energy injury was defined as an injury caused by a fall from a standing height, and others such as fall from a height, motor accidents were deemed as high-energy injury.

\section{Statistical analysis}

The categorical data were expressed as frequency $(n)$ and percentage (\%) and were evaluated by Chi-square test or Fisher's exact test. Continuous variables were expressed by mean and standard deviation (SD) and the difference was evaluated by Student $t$ test or MannWhitney $U$ test, as appropriate. A multivariate logistics regression analysis was used to identify the independent risk factors associated with occurrence of stroke, using the stepwise backward elimination method. The variables were remained in the final model when $p$ value less than 0.10 , and the correlation strength was indicated by odd ratio (OR) and 95\% confidence interval $(95 \% \mathrm{CI})$. The significance level was set as $p<0.05$. HosmerLemeshow $(\mathrm{H}-\mathrm{L})$ test was used to evaluate the fitting degree of the final logistics regression model, and $p>0.05$ represented the acceptable result. All tests were performed using SPSS21.0 (IBM, Armonk, NY, USA).

\section{Results}

\section{The general information}

Totally, 3743 patients were deemed as eligible and included, including 1592 males and 2151 females. The average age was 78.2 years, ranging from 65 to 104 years. During the hospitalization and follow-up period, 56 patients had a stroke, indicating an accumulative incidence rate of $1.5 \%$ (56/3743; 95\% CI, 1.1 to $1.9 \%)$.

Univariate analysis showed that the age of patients with stroke was significantly higher than that of the non-stroke group (80.3 vs 78.1, $p=0.001$ ). The incidence rate of stroke was higher among patients undergoing osteosynthesis than those undergoing THA (1.7\% vs $0.9 \%)$, although not significantly different $(p=0.103)$. Patients with a stroke had a comparable preoperative hospitalization stay for the hip fracture surgery as that of non-stroke patients (4.6 vs 4.3 days, $p=0.278$ ). There were no significant differences between both groups in BMI, smoking status, surgical methods, ASA classification, and others between the two groups $(p>0.05)$ (Table 1) either.

In the multivariate model, five independent risk factors were identified to be associated with postoperative stroke after hip fracture, including advanced age in 1year increment (OR, 1.32; 95\% CI, 1.08 to 1.48$)$, history of previous stroke (OR, 4.79; 95\% CI, 1.86 to 6.56), ASA III and above (OR, 2.62; 95\% CI, 1.27 to 3.68), long-term use of aspirin (OR, 3.63; 95\% CI, 1.41 to 4.78 ), and elevated RDW level (each increment of 1\%, OR, 1.21; 95\% CI, 1.02 to 1.36) (Table 2). As for other variables, we did not find their significant effect on the multivariate model. The H-L analysis demonstrated the good fitness of the final model $\left(X^{2}=3.186, p=0.623\right.$; Nagelkerke $R^{2}=0.402$ ).

\section{Discussion}

Stroke is a serious complication after hip fractures in the elderly and can lead to increased morbidity, mortality, and medical costs. Surgical treatment of acute hip fractures may increase the risk of stroke for a variety of reasons. In this study, we found the incidence rate of stroke was $1.5 \%$ following hip fracture surgeries. Several risk factors associated with the occurrence of postoperative stroke were identified, including advanced age, history of stroke, higher ASA grade, long-term use of aspirin, and elevated preoperative RDW.

Due to the differences in study design, data resource, patient characteristics, and the follow-up period, the incidence rates were reported to be greatly varied in literature. The National Trauma Data Bank of the USA included 37,584 elderly patients with hip fractures between 2011 and 2012 and identified 162 patients who had a stroke during hospitalization stay, representing an incidence rate of $0.4 \%$ [20]. In another study of elderly veterans, the incidence rate of stroke was found to be $1 \%$ during hospitalization; however, the study time of 1982 to 1993 and specifying at a special occupational group might compromise generalizability of the results [21]. The relatively lower incidence rate of stroke in both studies was largely attributable to the shorter follow-up period that was only in hospitalization stay. Recent studies have reported higher incidence rates of stroke after hip fracture, reaching $4 \%$ at the follow-up of 1 year [17, 19], about 2.5-fold higher than ours. Despite with various results reflecting the heterogeneity among studies, these studies did provide useful information about stroke after surgery of hip fractures, also aided in understanding of the higher rate of 1-year mortality or independence loss [22].

Advanced age was identified as an independent risk factor for stroke in our study, consistent with that of previous studies $[18,23]$. But this relationship does not exclude the confounding effects of factors other than those included in this study, such as increased prevalence of osteoporosis, cognitive impairment, or other medical conditions in elderly patients. It should also be noted that old age is a primary overlapping factor among hip fracture and stroke patients, and therefore, the role of advanced age as a risk factor in causing stroke might 
Table 1 Association between potential risk factors and stroke after hip fracture surgeries

\begin{tabular}{|c|c|c|c|}
\hline Variables & Number $(\%)$ of stroke $(n=56)$ & Number $(\%)$ of non-stroke $(n=3687)$ & $P$ \\
\hline Gender (male) & 19 (33.9) & $1573(42.7)$ & 0.189 \\
\hline Age (years) & $80.3 \pm 8.5$ & $78.1 \pm 11.4$ & 0.001 \\
\hline Living place & & & 0.482 \\
\hline Rural & $29(51.8)$ & $1735(47.1)$ & \\
\hline Urban & $27(48.2)$ & $1952(52.9)$ & \\
\hline BMI $\left(\mathbf{k g} / \mathrm{m}^{2}\right)$ & $24.7 \pm 5.6$ & $25.4 \pm 3.9$ & 0.672 \\
\hline $18.5-23.9$ & $24(42.9)$ & $1368(37.1)$ & 0.221 \\
\hline$<18.5$ & $5(8.9)$ & $198(5.4)$ & \\
\hline $24.0-27.9$ & $17(30.4)$ & $1595(43.3)$ & \\
\hline$\geq 28.0$ & $10(17.9)$ & $526(14.3)$ & \\
\hline Diabetes mellitus & $11(19.6)$ & $538(14.6)$ & 0.289 \\
\hline Hypertension & $19(33.9)$ & $895(24.3)$ & 0.095 \\
\hline Chronic heart disease & $7(12.5)$ & $362(9.8)$ & 0.504 \\
\hline Past stroke & $11(19.6)$ & $287(7.8)$ & 0.001 \\
\hline Chronic use of aspirin & $10(17.9)$ & $325(8.8)$ & 0.019 \\
\hline Injury mechanism (low-energy) & $53(94.6)$ & $3521(95.5)$ & 0.760 \\
\hline Preoperative stay & $4.6 \pm 3.2$ & $4.3 \pm 2.6$ & 0.278 \\
\hline Total hospital stay & $14.4 \pm 7.4$ & $15.1 \pm 7.9$ & 0.443 \\
\hline Intraoperative bleeding & $286.6 \pm 304.2$ & $278 \pm 187.1$ & 0.643 \\
\hline Surgical duration & $106.5 \pm 47.0$ & $97.8 \pm 51.4$ & 0.074 \\
\hline Cigarette smoking & $9(16.1)$ & $774(21.0)$ & 0.369 \\
\hline Alcohol consumption & $13(23.2)$ & $1402(38.0)$ & 0.023 \\
\hline Fracture type & & & 0.149 \\
\hline Femoral neck & $25(44.6)$ & $2005(54.3)$ & \\
\hline Intertrochanteric & $31(55.4)$ & $1686(45.7)$ & \\
\hline Procedure & & & 0.103 \\
\hline Osteosynthesis & $47(83.9)$ & $2742(74.4)$ & \\
\hline Arthroplasty & $9(16.1)$ & $945(25.6)$ & \\
\hline Anesthesia & & & 0.145 \\
\hline Local & $2(3.6)$ & $134(3.6)$ & \\
\hline Spinal & $23(41.1)$ & $1989(53.9)$ & \\
\hline General & $31(55.4)$ & $1564(42.4)$ & \\
\hline ASA class & & & 0.007 \\
\hline$|-| \mid$ & $31(55.4)$ & $2642(71.7)$ & \\
\hline III or above & $25(44.6)$ & $1045(28.3)$ & \\
\hline $\mathrm{TP}(\mathrm{g} / \mathrm{L})$ & $54.1 \pm 7.9$ & $59.2 \pm 7.2$ & 0.005 \\
\hline ALB (g/L) & $28.4 \pm 4.5$ & $33.6 \pm 5.5$ & $<0.001$ \\
\hline ALT (U/L) & $25.3 \pm 19.4$ & $24.5 \pm 23.7$ & 0.579 \\
\hline AST (U/L) & $26.7 \pm 16.4$ & $26.2 \pm 23.8$ & 0.752 \\
\hline FBG $(\mathrm{mmol} / \mathrm{L})$ & $5.1 \pm 2.2$ & $5.0 \pm 1.9$ & 0.896 \\
\hline TC $(\mathrm{mmol} / \mathrm{L})$ & $3.8 \pm 0.9$ & $3.5 \pm 0.7$ & 0.103 \\
\hline TG (mmol/L) & $1.3 \pm 0.6$ & $1.1 \pm 0.7$ & 0.164 \\
\hline LDL-C (mmol/L) & $2.2 \pm 0.6$ & $2.4 \pm 0.7$ & 0.489 \\
\hline HDL-C (mmol/L) & $0.9 \pm 0.4$ & $1.2 \pm 0.3$ & 0.016 \\
\hline
\end{tabular}


Table 1 Association between potential risk factors and stroke after hip fracture surgeries (Continued)

\begin{tabular}{|c|c|c|c|}
\hline Variables & Number (\%) of stroke $(n=56)$ & Number $(\%)$ of non-stroke $(n=3687)$ & $P$ \\
\hline VLDL (mmol/L) & $0.6 \pm 0.3$ & $0.5 \pm 0.3$ & 0.133 \\
\hline WBC $\left(10^{9} / \mathrm{L}\right)$ & $9.0 \pm 3.1$ & $8.7 \pm 3.3$ & 0.673 \\
\hline NEUT $\left(10^{9} / \mathrm{L}\right)$ & $6.9 \pm 2.9$ & $6.9 \pm 2.8$ & 0.907 \\
\hline $\operatorname{LYM}\left(10^{9} / \mathrm{L}\right)$ & $1.2 \pm 0.6$ & $1.1 \pm 0.6$ & 0.918 \\
\hline RBC (< lower limit) & $26(46.4)$ & $2078(56.4)$ & 0.137 \\
\hline HGB (< lower limit) & 19 (33.9) & $858(23.3)$ & 0.062 \\
\hline HCT (< lower limit) & $4(7.1)$ & $97(2.6)$ & 0.039 \\
\hline PLT $\left(<100 \times 10^{9} / \mathrm{L}\right)$ & $4(7.1)$ & $127(3.4)$ & 0.135 \\
\hline PDW (\%) & $15.7 \pm 3.4$ & $15.1 \pm 2.4$ & 0.176 \\
\hline RDW (\%) & $15.8 \pm 1.5$ & $14.1 \pm 1.8$ & 0.014 \\
\hline
\end{tabular}

$B M I$ Body mass index, ASA American Society of Anesthesiologists, RBC Red blood cell; reference range: female, 3.5-5.0/10 $12 / L ;$ males, 4.0-5.5/10 $12 / L$. $H G B$ Hemoglobin; reference range: females, $110-150 \mathrm{~g} / \mathrm{L} ;$ males, $120-160 \mathrm{~g} / \mathrm{L}$. FBG Fasting blood glucose, ALT Alkaline phosphatase, HCT Hematocrit; $40-50 \%$. WBC White blood cell, NEUT Neutrophile, LYM Lymphocyte, PLT Platelet; $100-300 \times 10^{9} / \mathrm{L}$. TP Total protein, ALB Albumin, GLOB Globulin, RDW Red cell distribution width, PDW Platelet distribution width, TC Total cholesterol, TG Triglyceride, $L D L-C$ Low-density lipoprotein, HDL-C High-density lipoprotein, VLDL Very low-density lipoprotein

not be pure and should be viewed in context of interactions between co-morbidities, impaired organ functions, and age [6], although some of them were adjusted in our multivariate model. Particular attention should be paid to patients with a history of previous strokes, in whom the risk of a recurrent stroke was increased by 13 times [24]. Therefore, patients with a previous history of stroke should be classified as an extremely high-risk group, which deserved more attention and optimization of medical conditions. It is suggested that for patients with recent stroke or transient ischemic attack, the surgical operation should be delayed for at least 9 months, using local anesthesia instead of general anesthesia, to avoid occurrence of perioperative hypotension and the recurrence of perioperative stroke [25].

ASA level is an important indicator for co-morbidities and anesthesia risk index. This study found a significant positive correlation between higher ASA level and postoperative stroke occurrence. Similar as our findings, previous studies found a positive correlation between the risk of stroke and the number of chronic diseases $[6$, 10]. Therefore, it is of significance to optimize surgical

Table 2 Multivariate analyses of risk factors associated with stroke after hip fracture surgeries

\begin{tabular}{lll}
\hline Variable & OR and $95 \% \mathrm{Cl}$ & $\boldsymbol{p}$ value \\
\hline Age (increase of each year) & $1.32(1.08$ to 1.48$)$ & 0.002 \\
Previous stroke & $4.79(1.86$ to 6.56$)$ & $<0.001$ \\
ASA III and above & $2.62(1.27$ to 3.68$)$ & 0.006 \\
Long-term use of aspirin & $3.63(1.41$ to 4.78$)$ & 0.011 \\
Elevated RDW level (each increment of $1 \%)$ & $1.21(1.02$ to 1.36$)$ & 0.027
\end{tabular}

ASA American Society of Anesthesiologists, OR Odd ratio, Cl Confidence interval, RDW Red cell distribution width conditions and control parameters for chronic diseases during hospitalization to reduce the incidence of stroke.

The use of anticoagulants or anti-platelet drugs are increasingly prevalent, due to their positive effects on reduction of thromboembolic events [26], but their risk in stroke has been always a controversy. Samuel et al. [20] demonstrated the increased $65 \%$ risk of stroke after long-term use of anticoagulants in elderly hip fracture patients, independent of other variables. Popa et al. [17] found aspirin use was not a significant predictor of postoperative stroke after adjustment for other variables and only considered it as a marker of increased cardiovascular risk. In this study, although we observed a significant association between aspirin and the stroke, this correlation should be treated cautiously because it might also be the reflection of previous history of stroke or other thromboembolic events. The role of long-term use of aspirin in cerebrovascular event requires prospective, larger sample-size cohort studies to confirm.

The association between laboratory RDW values and stroke has been demonstrated in previous studies [2729], but this is the first report specifying hip fractures. Lappegard et al. [27] evaluated 25,992 participants in a prospective cohort study, of whom 1152 participants had their first stroke at a median follow-up of 15.8 years. After adjusting for multiple variables, the authors found every $1 \%$ increase in RDW was associated with increased $13 \%$ risk of stroke, and participants with RDW values in the highest quartile had a $37 \%$ higher risk of stroke than those with RDW values in the lowest quartile. Moreover, Kim et al. [30] confirmed that in stroke patients, every $1 \%$ increase in RDW value was associated with the increased 1.3-fold mortality rate, and furthermore this effect persisted throughout the follow-up period ( $>1$ year). Therefore, close monitoring of this biomarker index is of 
great importance in evaluating the prognosis, not only occurrence of but even the death.

Despite a large sample and a relatively long follow-up period, this study suffered from several limitations. Firstly, this study was still unable to evaluate the effects of some infrequent medical conditions, such as renal insufficiency and chronic use of glucocorticoid. Secondly, we were unable to investigate the relationship between some complications and occurrence of stroke, including surgical site infection, deep venous thrombosis, and others. Thirdly, due to using the telephone visit, we could not know the accuracy in diagnosis of stroke and its subclassifications. Fourthly, the results of this study might not be extrapolated to others, due to the difference in race, ethnic, or the specific operative technique.

In summary, we found the incidence rate of stroke after surgery of hip fracture was $1.5 \%$ at the follow-up above 1 year and identified 5 independently associated risk factors: advanced age, history of previous stroke, ASA III and above, long-term use of aspirin, and elevated RDW level. Although most of them are not modifiable, they could provide data for construction of predictive models for stroke occurrence and aid in counseling patients regarding the stroke risk after operation.

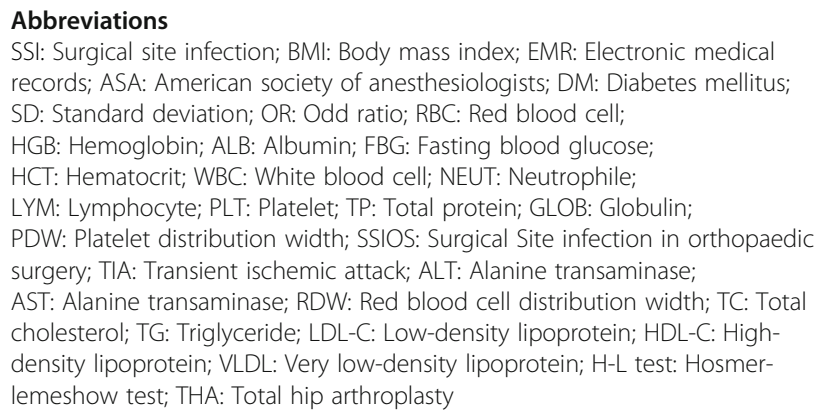

\section{Acknowledgements}

We are grateful to $Y$ Ling and $M$ Zhang of the Department of Orthopedics and to K Liu and X Zhang of the Department of Statistics and Applications for their kind assistance.

\section{Authors' contributions}

Hui Bu and Yingze Zhang designed the study. Yanbin Zhu and Wei Chen inquired the EMR for data on variables of interest, searched relevant literature, and analyzed and interpreted the data. Lili Yu and Yanbin Zhu wrote the manuscript and Hui Bu approved the final version of the manuscript. The authors read and approved the final manuscript.

\section{Funding}

The study was funded by 3-3-3 talent project for high-level talents of Hebei Province (A2017005073).

\section{Availability of data and materials}

All the data will be available upon motivated request to the corresponding author of the present paper.

\section{Ethics approval and consent to participate}

This study was approved by the ethics committee of the 3rd Hospital of Hebei Medical University. Informed consent was obtained from all the participants.

\section{Consent for publication}

Written informed consent was obtained from each patient to authorize the publication of their data.

\section{Competing interests}

The authors declare that they have no competing interests.

\section{Author details}

'Department of Neurology, The 2nd Hospital of Hebei Medical University, Shijiazhuang 050000, Hebei, People's Republic of China. ${ }^{2}$ Key Laboratory of Neurology of Hebei Province, Shijiazhuang 050000, Hebei, People's Republic of China. ${ }^{3}$ Department of Orthopaedic Surgery, The 3rd Hospital of Hebei Medical University, Shijiazhuang 050051, Hebei, People's Republic of China. ${ }^{4}$ Key Laboratory of Biomechanics of Hebei Province, Shijiazhuang 050051, Hebei, People's Republic of China. ${ }^{5}$ Chinese Academy of Engineering, Beijing 100088, People's Republic of China.

Received: 9 August 2020 Accepted: 10 September 2020

Published online: 18 September 2020

\section{References}

1. Johnell O, Kanis JA. An estimate of the worldwide prevalence, mortality and disability associated with hip fracture. Osteoporos Int. 2004;15(11):897-902.

2. Dhanwal DK, Dennison EM, Harvey NC, Cooper C. Epidemiology of hip fracture: worldwide geographic variation. Indian J Orthop. 2011:45(1):15-22.

3. Cooper C, Cole ZA, Holroyd CR, Earl SC, Harvey NC, Dennison EM, Melton L, Cummings SR, Kanis JA. Secular trends in the incidence of hip and other osteoporotic fractures. Osteoporos Int. 2011;22(5):1277-88.

4. Zhang Y. Clinical epidemiology of orthopaedic trauma (2nd edition). Stuttgart \& New York: Thieme; 2016.

5. Veronese N, Maggi S. Epidemiology and social costs of hip fracture. Injury. 2018;49(8):1458-60.

6. Pedersen AB, Ehrenstein V, Szepligeti SK, Sorensen HT. Hip Fracture, comorbidity, and the risk of myocardial infarction and stroke: a Danish nationwide cohort study, 1995-2015. J Bone Miner Res. 2017;32(12):2339-46.

7. Bohl DD, Samuel AM, Webb ML, Lukasiewicz AM, Ondeck NT, Basques BA, Anandasivam NS, Grauer JN. Timing of adverse events following geriatric hip fracture surgery: a study of 19,873 patients in the American College of Surgeons National Surgical Quality Improvement Program. Am J Orthop (Belle Mead NJ). 2018;47(9):1-13.

8. Lin HL, Lin HC, Tseng YF, Liao HH, Worly JA, Pan CY, Hsu CY. Hip fracture after first-ever stroke: a population-based study. Acta Neurol Scand. 2015; 131(3):158-63.

9. Yuan ZC, Mo H, Guan J, He JL, Wu ZJ. Risk of hip fracture following stroke, a meta-analysis of 13 cohort studies. Osteoporos Int. 2016;27(9):2673-9.

10. Glassou EN, Kjorholt KK, Hansen TB, Pedersen AB. Delay in surgery, risk of hospital-treated infections and the prognostic impact of comorbidity in hip fracture patients. A Danish nationwide cohort study, 2005-2016. Clin Epidemiol. 2019;11:383-95.

11. Choi YH, Kim DH, Kim TY, Lim TW, Kim SW, Yoo JH. Early postoperative delirium after hemiarthroplasty in elderly patients aged over 70 years with displaced femoral neck fracture. Clin Interv Aging. 2017;12:1835-42.

12. de Jong $L$, van Rijckevorsel V, Raats JW, Klem T, Kuijper TM, Roukema GR. Delirium after hip hemiarthroplasty for proximal femoral fractures in elderly patients: risk factors and clinical outcomes. Clin Interv Aging. 2019;14:427-35

13. Dolan MM, Hawkes WG, Zimmerman SI, Morrison RS, Gruber-Baldini AL, Hebel JR, Magaziner J. Delirium on hospital admission in aged hip fracture patients: prediction of mortality and 2-year functional outcomes. J Gerontol A Biol Sci Med Sci. 2000;55(9):M527-34.

14. Kalisvaart KJ, Vreeswijk R, de Jonghe JF, van der Ploeg T, van Gool WA, Eikelenboom P. Risk factors and prediction of postoperative delirium in elderly hip-surgery patients: implementation and validation of a medical risk factor model. J Am Geriatr Soc. 2006;54(5):817-22.

15. Zheng JQ, Lai HJ, Zheng CM, Yen YC, Lu KC, Hu CJ, Lee HH, Wang YH. Association of stroke subtypes with risk of hip fracture: a population-based study in Taiwan. Arch Osteoporos. 2017;12(1):104.

16. Rasouli MR, Tabatabaee RM, Maltenfort MG, Chen AF. Acute stroke after total joint arthroplasty: a population-based trend analysis. J Clin Anesth. 2016;34:15-20. 
17. Popa AS, Rabinstein AA, Huddleston PM, Larson DR, Gullerud RE, Huddleston JM. Predictors of ischemic stroke after hip operation: a population-based study. J Hosp Med. 2009;4(5):298-303.

18. An Q, Chen Z, Huo K, Su H, Qu QM. Risk factors for ischemic stroke post bone fracture. J Clin Neurosci. 2019;59:224-8.

19. Kang JH, Chung SD, Xirasagar S, Jaw FS, Lin HC. Increased risk of stroke in the year after a hip fracture: a population-based follow-up study. Stroke. 2011:42(2):336-41.

20. Samuel AM, Diaz-Collado PJ, Szolomayer LK, Nelson SJ, Webb ML, Lukasiewicz AM, Grauer JN. Incidence of and risk factors for inpatient stroke after hip fractures in the elderly. Orthopedics. 2018;41(1):e27-32.

21. Lawrence VA, Hilsenbeck SG, Noveck H, Poses RM, Carson JL. Medical complications and outcomes after hip fracture repair. Arch Intern Med. 2002;162(18):2053-7.

22. Brown RD, Whisnant JP, Sicks JD, O'Fallon WM, Wiebers DO. Stroke incidence, prevalence, and survival: secular trends in Rochester, Minnesota, through 1989. Stroke. 1996;27(3):373-80.

23. Bateman BT, Schumacher HC, Wang S, Shaefi S, Berman MF. Perioperative acute ischemic stroke in noncardiac and nonvascular surgery: incidence, risk factors, and outcomes. Anesthesiology. 2009;110(2):231-8.

24. Oza R, Rundell K, Garcellano M. Recurrent ischemic stroke: strategies for prevention. Am Fam Physician. 2017;96(7):436-40.

25. Boyer T, Sigaut S, Puybasset L, Deltour S, Clarencon F, Degos V. From preoperative evaluation to stroke center: management of postoperative acute ischemic stroke. Anaesth Crit Care Pain Med. 2016;35(4):299-305.

26. CAST (Chinese Acute Stroke Trial) Collaborative Group. CAST: randomised placebo-controlled trial of early aspirin use in 20,000 patients with acute ischaemic stroke. Lancet (London, England). 1997;349(9066):1641-9.

27. Lappegard J, Ellingsen TS, Skjelbakken T, Mathiesen EB, Njolstad I, Wilsgaard T, Brox J, Braekkan SK, Hansen JB. Red cell distribution width is associated with future risk of incident stroke. The tromso study. Thromb Haemost. 2016;115(1):126-34.

28. Duchnowski P, Hryniewiecki T, Kusmierczyk M, Szymanski P. Red cell distribution width is a prognostic marker of perioperative stroke in patients undergoing cardiac valve surgery. Interact Cardiovasc Thorac Surg. 2017; 25(6):925-9.

29. Turcato G, Cervellin G, Cappellari M, Bonora A, Zannoni M, Bovi P, Ricci G Lippi G. Early function decline after ischemic stroke can be predicted by a nomogram based on age, use of thrombolysis, RDW and NIHSS score at admission. J Thromb Thrombolysis. 2017;43(3):394-400.

30. Kim J, Kim YD, Song TJ, Park JH, Lee HS, Nam CM, Nam HS, Heo JH. Red blood cell distribution width is associated with poor clinical outcome in acute cerebral infarction. Thromb Haemost. 2012;108(2):349-56

\section{Publisher's Note}

Springer Nature remains neutral with regard to jurisdictional claims in published maps and institutional affiliations.

Ready to submit your research? Choose BMC and benefit from:

- fast, convenient online submission

- thorough peer review by experienced researchers in your field

- rapid publication on acceptance

- support for research data, including large and complex data types

- gold Open Access which fosters wider collaboration and increased citations

- maximum visibility for your research: over $100 \mathrm{M}$ website views per year

At $\mathrm{BMC}$, research is always in progress.

Learn more biomedcentral.com/submissions 